\title{
BMJ Open Effectiveness of combined exercise and nutrition interventions in prefrail or frail older hospitalised patients: a systematic review and meta-analysis
}

\author{
Chad Yixian Han (D , ${ }^{1}$ Michelle Miller, ${ }^{1}$ Alison Yaxley, ${ }^{1}$ Claire Baldwin, ${ }^{1}$ \\ Richard Woodman, ${ }^{2}$ Yogesh Sharma (D) ${ }^{3,4}$
}

To cite: Han CY, Miller M, Yaxley $A$, et al. Effectiveness of combined exercise and nutrition interventions in prefrail or frail older hospitalised patients: a systematic review and meta-analysis. BMJ Open 2020;10:e040146. doi:10.1136/ bmjopen-2020-040146

- Prepublication history and additional material for this paper is available online. To view these files, please visit the journal online (http://dx.doi.org/10. 1136/bmjopen-2020-040146)

Received 07 May 2020 Revised 04 November 2020 Accepted 18 November 2020

\section{Check for updates}

(c) Author(s) (or their employer(s)) 2020. Re-use permitted under CC BY-NC. No commercial re-use. See rights and permissions. Published by BMJ.

${ }^{1}$ Caring Futures Institute, College of Nursing and Health Sciences, Flinders University, Adelaide,

South Australia, Australia

${ }^{2}$ Flinders Centre for Epidemiology and Biostatistics, Flinders University, Adelaide, South Australia, Australia ${ }^{3}$ Department of General Medicine, Flinders Medical Centre, Adelaide, South Australia, Australia

${ }^{4}$ College of Medicine and Public Health, Flinders University, Adelaide, South Australia, Australia

Correspondence to Chad Yixian Han; chad.han@flinders.edu.au

\section{ABSTRACT}

Objectives To determine the effectiveness of combined exercise-nutrition interventions in prefrail/frail hospitalised older adults on frailty, frailty-related indicators, quality of life (QoL), falls and its cost-effectiveness.

Design Randomised controlled trials (RCTs) of combined exercise-nutrition interventions on hospitalised prefrail/ frail older adults $\geq 65$ years were collated from MEDLINE, Emcare, CINAHL, Ageline, Scopus, Cochrane and PEDro on 10 0ctober 2019. The methodological quality was appraised, and data were summarised descriptively or by meta-analysis using a fixed effects model. The standardised mean difference (SMD) or difference of means (MD) with $95 \%$ Cls was calculated.

Results Twenty articles from 11 RCTs experimenting exercise-nutrition interventions on hospitalised older adults were included. Seven articles were suitable for the meta-analyses. One study had low risk of bias and found improvements in physical performance and frailty-related biomarkers. Exercise interventions were mostly supervised by a physiotherapist, focusing on strength, ranging 2-5 times/week, of 20-90 min duration. Most nutrition interventions involved counselling and supplementation but had dietitian supervision in only three studies. The meta-analyses suggest that participants who received exercise-nutrition intervention had greater reduction in frailty scores $(n=3$, SMD 0.25 ; $95 \% \mathrm{Cl} 0.03$ to $0.46 ; \mathrm{p}=0.02$ ) and improvement in short physical performance battery (SPPB) scores $(n=3, M D$ $0.48 ; 95 \% \mathrm{Cl} 0.12$ to $0.84 ; p=0.008$ ) compared with standard care. Only the chair-stand test $(n=3)$ out of the three SPPB components was significantly improved (MD 0.26 ; $95 \% \mathrm{Cl} 0.09$ to $0.43 ; \mathrm{p}=0.003$ ). Patients were more independent in activities of daily living in intervention groups, but high heterogeneity was observed $\left(1^{2}=96 \%\right.$, $p<0.001)$. The pooled effect for handgrip $(n=3) \pm k n e e$ extension muscle strength $(n=4)$ was not statistically significant. Nutritional status, cognition, biomarkers, QoL, falls and cost-effectiveness were summarised descriptively due to insufficient data.

Conclusions There is evidence, albeit weak, showing that exercise-nutrition interventions are effective to improve frailty and frailty-related indicators in hospitalised older adults.
Strengths and limitations of this study

- This is the first comprehensive systematic review with meta-analysis on the effectiveness of exercisenutrition interventions on frailty and outcomes related to frailty in hospitalised and prefrail/frail older adults.

- Only randomised controlled trials describing existing exercise-nutrition interventions in prefrail/frail older hospitalised patients were included.

- There was a moderate risk of bias for most included studies such that the findings of this review are inconclusive, making it difficult to draw firm conclusions.

\section{INTRODUCTION}

Frailty is a major contributor to late-life disability as it leads to loss of independence. ${ }^{1}$ It is also associated with poor health outcomes, and, increased healthcare costs and service use. ${ }^{1}$ Frailty has been defined for clinical research by Fried $e t a l^{2}$ as a combination of unintentional weight loss, weakness, exhaustion, slowness and reduced physical activity. Prefrailty is a stage before frailty, where one or two of the five aforementioned symptoms are present. ${ }^{2}$ There are no gold standard in the clinical care setting to define frailty or prefrailty but is commonly understood as age-related physiological decline, resulting in increased vulnerability to health crises. ${ }^{3}$ Older adults (aged >65 years) that have been classified as frail and are hospitalised, have a threefold higher risk of readmission or death, as compared with the younger population. ${ }^{4}$ The management of older adults who are frail has an incremental effect on health expenditures with an additional equivalent of $\$$ A2400 per frail patient per year. ${ }^{5}$ With $21 \%$ of the population over 65 years estimated to be frail and $48 \%$ estimated to be prefrail, 
concerns of economic impact are compounded by an ageing population. ${ }^{6}$

Exercise and nutrition are inextricably linked, in particular strength training can address component issues of the frail phenotype. ${ }^{7}$ Yet evidence supporting the effectiveness of exercise-nutrition interventions for reversal of frailty is limited to community-dwelling older adults. ${ }^{8}$ In a study of community participants, a 3-month combined exercise-nutrition intervention resulted in a significant reversal of frailty (reduction in Fried frailty score) at 6 months, compared with the control group (betweengroup difference $-0.34 ; 95 \% \mathrm{CI}-0.52$ to $-0.16 ; \mathrm{p}<0.001){ }^{9}$ The combination of exercise therapy and dietary intervention in older adults who are frail, has also been reported to increase muscle strength (knee extension betweengroup difference $1.84 \mathrm{~kg}, 95 \% \mathrm{CI} 0.17$ to $3.51, \mathrm{p}=0.03)^{10}$ and improve nutritional status (Mini Nutritional Assessment (MNA) Short Form between-group difference 1.4, $95 \%$ CI 0.9 to $1.9, \mathrm{p}<0.01) .{ }^{11}$

A recent meta-analysis suggested that although effective, exercise combined with nutrition was not more effective in treating frailty than exercise alone. ${ }^{12}$ However, the majority of included studies were conducted in a community setting, with only $15 \%$ of older adults either hospitalised or recruited from acute care settings. No study has systematically evaluated evidence for interventions that commence during acute hospitalisation or early postdischarge (in the high-risk period for posthospital syndrome).

Hospitalisation is a vulnerable period, especially for older adults who are frail and therefore at higher risk of functional loss, ${ }^{13}$ malnutrition ${ }^{1415}$ and further decline in frailty status. Malnutrition is ubiquitous in older hospitalised patients with a prevalence as high as $50 \% .{ }^{16}$ Since many domains of frailty are attributed to poor nutrition, ${ }^{17}$ the effect of nutrition intervention when combined with exercise, may be more significant in the hospitalised population. ${ }^{17}$ Also, a recent review suggests that nutrition support, provided by a multidisciplinary team, may have a positive impact on mortality and quality of life (QoL) in hospitalised older adult patients. ${ }^{18}$ Nutritional therapy extends beyond protein or nutrition supplementation as reported in previous studies and may be more effective as part of individualised medical nutrition therapies involving dietitians to improve diet adequacy. ${ }^{19}$

This study aims to determine the effectiveness of combined exercise-nutrition interventions on (1) frailty, (2) frailty-related indicators, falls, QoL and (3) its costeffectiveness on prefrail or frail hospitalised older adults.

\section{MATERIALS AND METHODS}

\section{Protocol and registration}

The protocol for this review was compliant with Cochrane systematic review guidelines, ${ }^{20}$ and registered with the International Prospective Register of Systematic Reviews, CRD42020153934. The study is reported according to Preferred Reporting Items for Systematic Reviews and
Meta-Analyses guidelines. ${ }^{21}$ Patients and/or members of the public were not involved in this study.

\section{Search methods}

Systematic searches of electronic databases (MEDLINE, Emcare, CINAHL, Ageline, Scopus, Cochrane and PEDro) were conducted by the lead author (CYH) from inception until 10 October 2019 using search strategies reviewed by an academic librarian (search queries available in online supplemental file 1). Additionally, related citations to eligible items were identified using the suggested related citation function in PubMed. Reference lists of eligible items were also screened.

\section{Inclusion and exclusion criteria}

The inclusion criteria were: (1) randomised controlled trials (RCTs); (2) inclusion of prefrail or frail participants (as defined by study authors); (3) recruitment of older adult inpatients and/or those hospitalised within the past 30 days of recruitment; (4) interventions that started while patients were admitted and continued in the community/ posthospitalisation, or, commenced within 30 days of hospital discharge; (5) interventions that involved both physical exercises and nutritional interventions (dietary modifications/education/training alone or combined with oral nutrition supplementation); (6) measured frailty with an assessment tool or at least one indicator relevant to frailty (nutritional status, physical function, cognitive function and mood, physical activity level or biomarkers, falls and QoL and/or economic analysis of interventions). Studies were excluded if they described protocols with no pilot outcomes, interventions delivered as a part of a palliative care programme or interventions solely designed to facilitate discharge planning (eg, telephone support services, providing no prefrailty or frailty intervention element), recruited participants admitted following a mental health episode.

\section{Study selection and data extraction}

Covidence $^{22}$ was used to manage citations for title and abstract, and full-text screening, in duplicate $(\mathrm{CYH}$ and YS, online supplemental file 1). The reviewers were unblinded to authors, journals and countries of origin. Any disagreement was resolved through discussion or consensus opinion with the other authors. A data extraction form was developed a priori by the research team, such that two researchers (CYH and YS) performed data extraction independently, on eligible full-text articles. Where available, the continuous data were extracted as (1) mean change with SD, SE or 95\% CI, or (2) mean or median values with $\mathrm{SD}, \mathrm{SE}$ or IQR postintervention. If the required data were not reported within a publication (including change in means for outcomes of interest), the authors were emailed to request for it.

\section{Quality of the studies}

The risk of bias in the individual studies was assessed by the revised Cochrane risk-of-bias tool for randomised trials (RoB-2) by two researchers (CYH and YS) 
independently. ${ }^{23}$ Any disagreements were resolved by discussion or if required with consensus of a third reviewer. The Cochrane risk-of-bias tool is widely used to assess RCTs for best practice. ${ }^{24}$ Studies were given an overall risk-of-bias judgement of low, some concerns or high. Overall risk of bias was determined as having 'some concerns' if any one of the risks of bias domains was rated as having 'some concerns'. Likewise, studies were deemed to have an overall high risk of bias if any one domain had a high risk of bias.

\section{Data synthesis and statistical analyses}

Where possible, a meta-analysis was performed; continuous outcome data were pooled and reported as either the difference of means (MD) if the same outcome assessment tools were used or the standardised mean difference (SMD) if different outcome assessment tools were used, and the $95 \% \mathrm{CI}$, if there were two or more studies. The SMD is the mean difference when the outcome for each study is standardised to have mean zero and $\mathrm{SD}=1$. Studies presenting $\mathrm{SE}$ were converted to $\mathrm{SD}$ via the conversion formula. ${ }^{20}$ The fixed-effect meta-analyses were carried out with Cochrane Review Manager (RevMan) V.5.3. ${ }^{25} \mathrm{~A} \mathrm{p}$ value of $<0.05$ was considered statistically significant. The variability between studies (heterogeneity) was assessed by $\mathrm{I}^{2}$ and its $95 \% \mathrm{CI}^{26}$ For studies with unobtainable missing, or incomparable data, results were qualitatively synthesised.

\section{Patient and public involvement}

No patients were involved in this study

\section{RESULTS}

\section{Study selection}

The flow of studies through the review process is summarised in figure 1 . Twenty articles reporting on 11 studies were eligible for data synthesis and analysis. Three of 11 studies presented results from their cohort across separate publications. First, Villareal et $a l^{27}$ reported on physical functioning outcomes with biomarker results in the publication of Armamento-Villareal et al. ${ }^{28}$ Second, Cameron et $a l^{29}$ reported on frailty and some physical function outcomes, with other physical function outcomes in a secondary publication, ${ }^{30}$ fall rates ${ }^{31}$ and cost-analysis in another. ${ }^{32}$ Third, Luger $e t a l^{33}$ reported on frailty and nutritional status, with physical functioning outcomes across two other publications, ${ }^{345}$ fall efficacy ${ }^{36}$, QoL $^{37}$ and biomarkers. ${ }^{38}$ For clarity, the primary articles that report frailty or physical function outcomes are cited for descriptive data in tables 1-3 while individual articles are cited for synthesis of outcome results.

\section{Study and sample characteristics}

Details of study characteristics are available in table 1 . Across all studies, a total of 2307 participants were investigated. Most studies reported that patients were recruited from hospital wards $(n=7)^{2939-44}$ while the other four studies ${ }^{27334546}$ included patients that were recruited from hospital wards and community. Seven studies included only frail participants, ${ }^{27} 2941-4446$ and the remaining four studies 33394045 included frail, prefrail and non-frail participants. The Fried frailty phenotype criteria ${ }^{2}$ were used most frequently to classify frailty $(n=4),{ }^{29} 394045$ with participants considered non-frail, prefrail or frail if $0,1-2,3-5$ criteria were present, respectively. Luger et al used the Frailty Instrument for Primary Care of the Survey of Health, Ageing, and Retirement in Europe (SHARE-FI), ${ }^{33}$ which integrates components of exhaustion, appetite, handgrip strength, walking difficulties and physical activity. ${ }^{47}$ Five studies did not report any assessment method to define frailty. ${ }^{41-44} 46$ One study used a combination of three tools-modified Physical Performance Test, the measurement of $\mathrm{VO}_{2}$ peak and the Functional Status Questionnaire. ${ }^{27}$

\section{Risk of bias within individual studies}

Table 2 outlines the risk of bias in individual studies. One study ${ }^{27}$ had a low risk of bias and one study ${ }^{42}$ had a high risk of bias (including unblinded secondary outcome assessment and insufficient detail on standard care in control groups across recruitment sites). The other nine studies $^{29} 33$ 39-41 43-46 were rated as having some concerns overall, of which five could have been improved in $\geq 1$ domain. The remaining four studies ${ }^{27} 314042$ that were rated as having 'some concerns' overall, had risk in only one domain with the most common reason being failure to blind intervention/allocated group to participants. Examples of other concerns about risk of bias included: assessors being aware of the group allocation ${ }^{33}$ (measurement of outcomes domain); or a lack of information about participants/researcher blinding to group allocation. ${ }^{27} 2945$

\section{Characteristics of exercise intervention component}

Characteristics of the exercise interventions used in studies are outlined in table 3 , and included combinations of the following: supervised individual exercises $(n=10),{ }^{27} 29$ 39-46 group exercises $(n=3),{ }^{27} 4246$ education including support with resources (digital versatile disc or visual aid instruction booklet, $\mathrm{n}=2$ ), ${ }^{33} 39$ and motivational interviewing using a standardised protocol $(n=1){ }^{33}$ Three studies ${ }^{404} 45$ had inpatient only interventions, five $\mathrm{S}^{39424446}$ had interventions that extended from inpatient to postdischarge, two $^{29}{ }^{33}$ studies offered the intervention postdischarge only and one $\mathrm{e}^{27}$ did not report.

In the majority of studies $(n=9)$, the exercise component was delivered by a physiotherapist. ${ }^{27}{ }^{39-46}$ Two studies used trained fitness instructors, ${ }^{39} 42$ and another engaged lay volunteers who received training for the study. ${ }^{33}$ All studies included strength exercises as part of their interventions. Three studies described guidance on training intensity based on repetition maximums (RM) between $40 \%$ and $80 \% .{ }^{27} 4245$ Other components of exercise programmes included aerobic fitness, ${ }^{27} 293940$ flexibility ${ }^{27} 3940$ and/or balance. ${ }^{2729} 3940$ The frequency of interventions ranged 


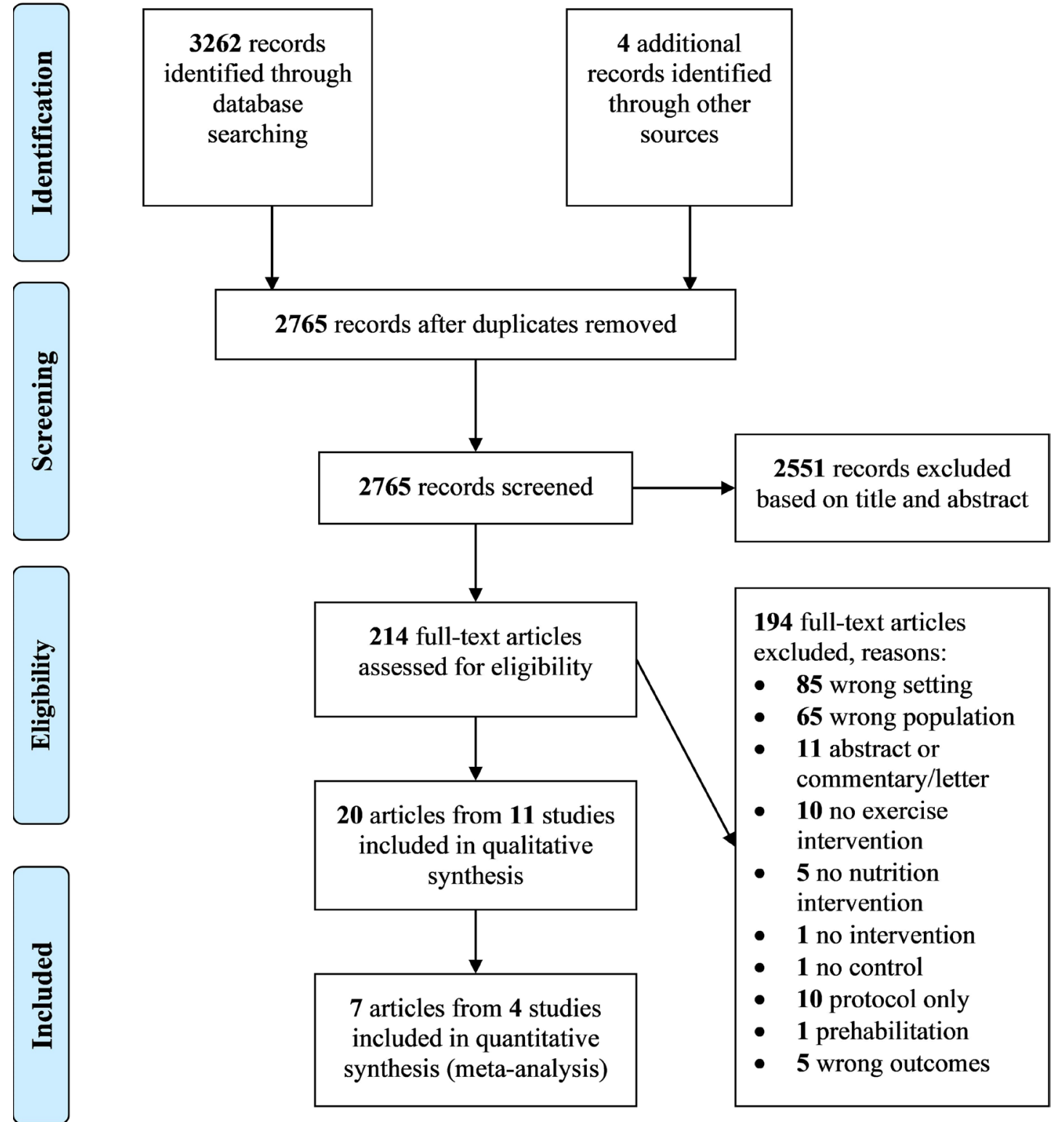

Figure 1 Flow diagram illustrating results of the search and study selection process as described in the Preferred Reporting Items for Systematic Reviews and Meta-Analyses statement.

from two 3339424546 to five ${ }^{2943}$ sessions a week, lasting between $20^{414445}$ to $90 \mathrm{~min}^{27}$ each. The duration of exercise intervention varied from 6 weeks ${ }^{46}$ to 1 year. ${ }^{27} 293942$

\section{Characteristics of nutrition intervention component}

Characteristics of the nutritional interventions used in studies, are outlined in table 3 , and included combinations of the following: nutrition counselling $(\mathrm{n}=8),{ }^{27} 293341-4446$ oral nutrition and/or multivitamin/mineral supplements $(\mathrm{n}=7),{ }^{27} 2940-44$ meal programmes $(\mathrm{n}=3),{ }^{29} 4143$ self-guided education materials $(n=2){ }^{3942}$ The most common combination of nutrition intervention was counselling with oral nutrition and/or multivitamin/mineral supplements $(n=5) .{ }^{27} 414446$ Five of nine nutrition counselling interventions were performed by dietitians. ${ }^{27414446}$ Other studies used trained lay volunteers, ${ }^{33}$ a researcher/nutrition therapist or did not specify a skill set for who delivered the counselling. ${ }^{45}$

All counselling interventions aimed to achieve adequate dietary targets for energy, protein and other nutrients. One study on obese frail participants aimed for calorie deficit but ensured that all achieved $1 \mathrm{~g} / \mathrm{kg} /$ day of protein in the intervention group. ${ }^{27}$ The reported frequency of counselling ranged from twice a week ${ }^{3345}$ to fortnightly. ${ }^{414}$ Oral nutrition supplements (ONS) were the most common supplements prescribed to intervention group participants $(\mathrm{n}=6),{ }^{27} 4041434446$ typically providing $200-300 \mathrm{kcal}$ and $12-24 \mathrm{~g}$ protein per serve with a frequency of consumption up to seven times a week $^{4043}$ or as prescribed by dietitians ${ }^{27414446}$ to cover any identified deficits between individually estimated energy and protein requirements and actual intake. Calcium and 


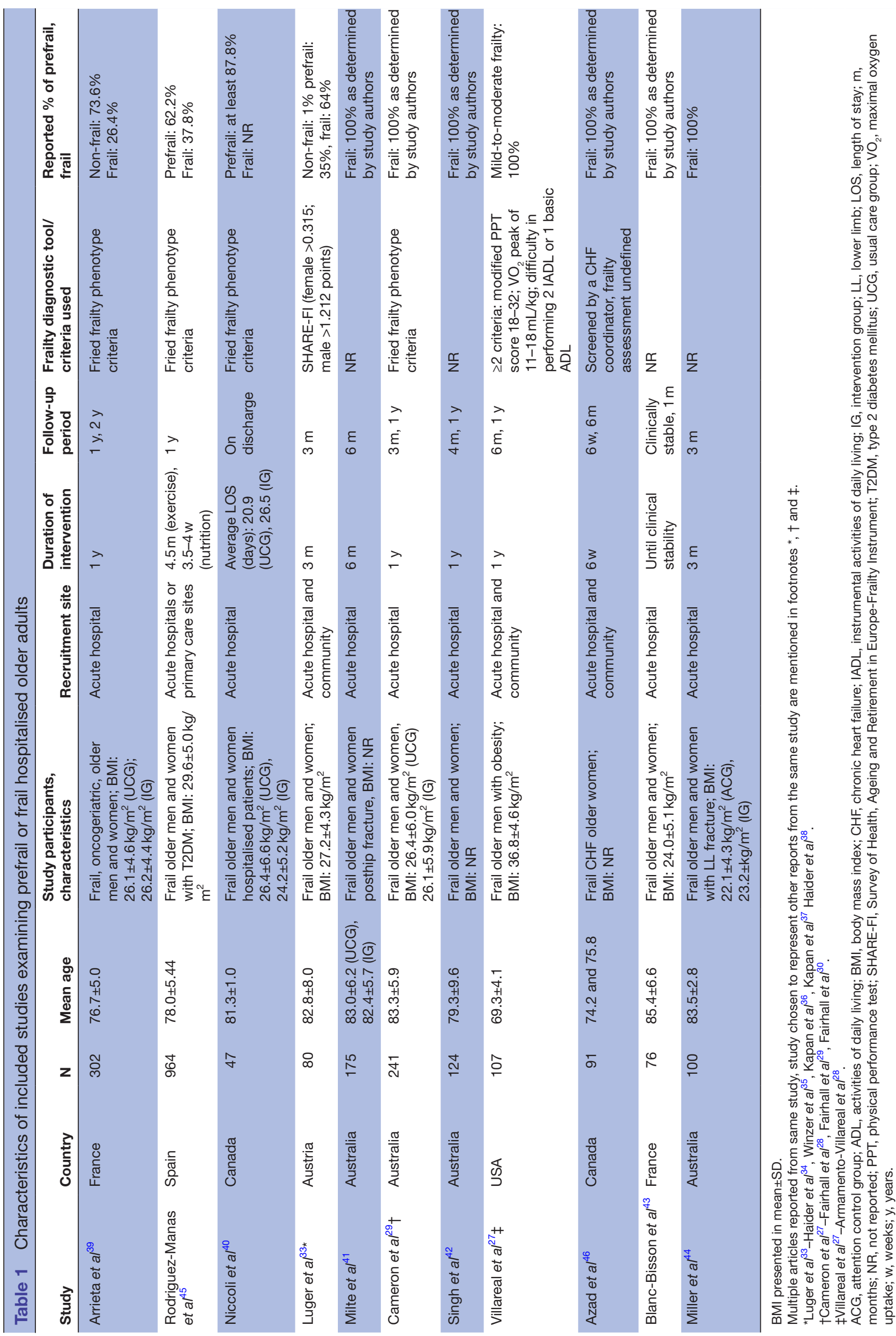


Table 2 Assessment of methodology quality of included studies using Cochrane risk-of-bias 2.0 tool

Cochrane risk-of-bias 2.0 tool assessment domains

\begin{tabular}{|c|c|c|c|c|c|c|}
\hline Study & \multicolumn{6}{|c|}{ Cochrane risk-of-bias 2.0 tool assessment domains } \\
\hline Rodriguez-Manas et al ${ }^{45}$ & + & $?$ & + & $?$ & + & $?$ \\
\hline Niccoli et $a l^{40}$ & $?$ & $?$ & + & $?$ & + & $?$ \\
\hline Cameron et $\mathrm{al}^{29} \dagger$ & + & $?$ & + & + & + & $?$ \\
\hline Singh et $a l^{42}$ & + & $?$ & + & - & + & - \\
\hline Villareal et $a l^{27} \ddagger$ & + & + & + & + & + & + \\
\hline Azad et $a l^{46}$ & + & $?$ & + & $?$ & + & $?$ \\
\hline
\end{tabular}

Key: +=low risk of bias; ?=some concerns of risk of bias; $-=$ high risk of bias.

Deviations from intended interventions (effect starting and adhering to intervention).

Multiple articles reported from same study, study chosen to represent other reports from the same study are mentioned in footnotes * $\dagger$ and $\ddagger$.

${ }^{*}$ Luger et $a l^{33}$-Haider et $a l^{34}$, Winzer et $a l^{35}$, Kapan et $a l^{36}$, Kapan et $a l^{37}$, Haider et $a l^{38}$.

†Cameron et $a l^{29}$-Fairhall et $a l^{30}$, Fairhall et $a l^{31}$, Fairhall et $a l^{32}$.

$\neq$ †illareal et $a l^{27}$-Armamento-Villareal et al ${ }^{28}$.

vitamin $\mathrm{D}$ were the two most commonly supplemented micronutrients ${ }^{2742}$ at doses in the range of $1200-1500 \mathrm{mg}$ / day and $1000 \mathrm{IU} /$ day, respectively. Meal programmes were either delivered as inpatient specialised geriatric meals providing $1800-2000 \mathrm{kcal} /$ day or home-delivered meal programmes. ${ }^{29} 4143$

\section{Frailty outcomes}

Data on frailty outcomes were available for quantitative analysis from three studies. ${ }^{29} 3340$ The meta-analysis is presented in figure 2 and suggested that participants who received exercise-nutrition intervention had a greater reduction in frailty score compared with those who received standard care (SMD 0.25; 95\% CI 0.03 to 0.46 ; $\mathrm{p}=0.02)$; no heterogeneity was observed $\left(\mathrm{I}^{2}=0 \% ; \mathrm{p}=0.58\right)$.

\section{Physical functioning outcomes}

Short physical performance battery

Data on the SPPB were available for quantitative analysis from three studies, ${ }^{29} 4548$ with results from the meta-analysis presented in figure 3. Participants who received exercisenutrition intervention had a statistically significant improvement in SPPB score, compared with those that received standard care (MD 0.48; $95 \%$ CI 0.12 to $0.84 ; \mathrm{p}=0.008$ ), with moderate heterogeneity ${ }^{20}$ observed $\left(\mathrm{I}^{2}=52 \% ; \mathrm{p}=0.13\right) .{ }^{2032} 33$ The analysis of SPPB components across all studies showed no statistically significant differences in gait speed ${ }^{29} 404548$ (MD 0.02; 95\% CI -0.02 to $0.06 ; \mathrm{p}=0.31 ; \mathrm{I}^{2}=37 \%, \mathrm{p}=0.19$ ) or balance ${ }^{294548}$ (MD 0.13; 95\% CI -0.04 to $0.30 ; \mathrm{p}=0.14$; $\mathrm{I}^{2}=0 \%, \mathrm{p}=0.22$ ) between groups. There were significantly greater improvements in chair stand test results ${ }^{29} 4548$ in the intervention group as compared with the control (MD 0.26;
95\% CI 0.09 to $0.43 ; \mathrm{p}=0.003 ; \mathrm{I}^{2}=23 \%, \mathrm{p}=0.23$ ). Two studies that were not suitable for meta-analysis (as data could not be provided by authors ${ }^{39}$ and a different measurement was used ${ }^{27}$ ) are instead qualitatively described. Arrieta $e t$ al reported no significant differences between groups in the percentage of participants who had a $\geq 1$ point decrease in SPPB score at 1 and 2 years $(\mathrm{p}=0.772, \mathrm{p}=0.057$, respectively) ${ }^{39}$ With use of an alternative measure of physical function (modified physical performance test-includes book lift, put on and take off a coat, pick up a penny, chair rise, turn 360, 50-foot walk, 10 steps of stairs, 4 flight of stairs and progressive Romberg test), Villareal et $a l^{27}$ reported a significant improvement in their exercise-nutrition interventions group as compared with exercise only $(\mathrm{p}=0.04)$, nutrition only $(\mathrm{p}<0.001)$ or controls.

\section{Activities of daily living}

Data on activities of daily living (ADL) from three studies ${ }^{30} 3545$ underwent meta-analysis, from which participants who received exercise-nutrition intervention were determined to have greater ADL independence postintervention than those who received standard care (SMD 1.06 ; $95 \%$ CI 0.91 to 1.20 ; $\mathrm{p}<0.001$, figure 3 ). However, high heterogeneity was observed $\left(\mathrm{I}^{2}=96 \%, \mathrm{p}<0.001\right)$. As such, additional random effects model was performed (SMD 0.80 ; $95 \%$ CI 0.00 to 1.60 ; $\mathrm{p}<0.001$; online supplemental file 2). Data from two studies ${ }^{434}$ were unavailable to be included the meta-analysis. One study ${ }^{42}$ was excluded due to high risk of bias in outcome measurements but reported that basic ADL declined lesser $(p<0.0001)$ in the intervention versus control group. 
Table 3 Characteristics of exercise and nutrition intervention and controls of included studies

\begin{tabular}{ll}
\hline Study & Exercise intervention \\
\hline Arrieta et $\mathrm{a}^{39}$ & Type: strength-intensity range from low to \\
& high, starting at 10 repetition per exercise \\
& (UL, LL) with option of progressive loading. \\
& Aerobic, flexibility, balance-intensity \\
& individualised. \\
& Frequency: 2 sessions/week, duration per \\
& session NR+home exercises duration NR. \\
& Setting: inpatient (supervised, \\
& individual)+postdischarge (unsupervised, \\
& individual). \\
& Additional support reported: phone consults \\
& (by trainer $2 \times /$ month for first 6 months then \\
& monthly for 1 year); education resource.
\end{tabular}

Rodriguez-Manas et al ${ }^{45}$ Type: strength $-40 \%-80 \%$ of estimated 1 $\mathrm{RM}, 8-10$ repetitions (LL). Frequency: 2 weeks pretraining followed by 16 -week programme of 2 days/week; 20-30 min/sessions.

Setting: inpatient (supervised, individual).

$\begin{array}{ll}\text { Niccoli et al }{ }^{40} & \text { Type: strength, aerobic, flexibility, } \\ & \text { balance-intensity and target muscle group } \\ & \text { individualised based on patient's baseline } \\ & \text { assessment. } \\ & \text { Frequency: individualised based on patient's } \\ & \text { baseline assessment. } \\ & \text { Setting: inpatient (supervised, individual). }\end{array}$

Luger et $a l^{33 *}$

Type: strength-2 sets of 15 repetitions (UL, LL) until muscular exhaustion.

Frequency: $2 \times /$ week, $>30$ min each session. Setting: postdischarge (supervised, individual).

Additional support reported: physical education (2-3 times/week, $30 \mathrm{~min}$ each session); exercise education resource (demonstration DVD); motivational interviewing.

\begin{tabular}{|c|c|c|c|}
\hline Milte et $a l^{41}$ & $\begin{array}{l}\text { Type: strength, balance (Otago exercise } \\
\text { programme)-intensity and repetitions NR, at } \\
\text { the discretion of the treating physiotherapist } \\
\text { (LL). } \\
\text { Frequency: } 3 \text { x/week, } 20-30 \mathrm{~min} / \text { session for } \\
12 \text { weeks. } \\
\text { Setting: inpatient (supervised, } \\
\text { individual)+postdischarge (supervised, } \\
\text { individual). }\end{array}$ & $\begin{array}{l}\text { Nutrition counselling: individualised } \\
\text { nutrition therapy aimed at improving energy } \\
\text { and protein intake to meet requirements by } \\
\text { dietitian who visits fortnightly. } \\
\text { Meal programme: ordered as deemed } \\
\text { necessary by dietitian. } \\
\text { Supplements: commercial ONS } \\
\text { recommended if needed by dietitian. }\end{array}$ & $\begin{array}{l}\text { Usual care: usual rehabilitation } \\
\text { programme recommended during } \\
\text { hospitalisation, social visits } \\
\text { weekly from trial staff and generic } \\
\text { nutrition, exercise and falls } \\
\text { prevention information. }\end{array}$ \\
\hline Singh et $a l^{42}$ & $\begin{array}{l}\text { Type: strength- } 80 \% \text { of most recent } 1 \text { RM or } \\
\text { RPE < } 15,3 \text { sets of } 8 \text { repetitions (UL, LL). } \\
\text { Frequency: } 2 \text { sessions/week, session } \\
\text { duration NR, over average of } 80 \text { sessions in } \\
1 \text { year, start as early as postassessment in } \\
\text { hospital or at home. } \\
\text { Setting: inpatient (supervised, } \\
\text { individual)+(supervised, group-based). } \\
\text { Additional support reported: monthly phone } \\
\text { consults. }\end{array}$ & $\begin{array}{l}\text { Nutrition counselling: counselling on } \\
\text { increase in diet quality, frequency NR. } \\
\text { Supplements: ONS } \pm \text { dietary advice to } \\
\text { increase daily energy ( } 400-600 \text { kcal) and } \\
\text { protein ( } 20 \text { g/day) intake. } \\
\text { For those calcium or vitamin D deficient } \\
(52 \%), 12 \text { months of vitamin D orally } \\
\text { ( } 1000 \mathrm{IU} / \text { day) or calcium ( } 1200 \mathrm{mg} / \text { day) and } \\
\text { vitamin D combination supplement. } \\
\text { Self-guided nutrition resource: food } \\
\text { sources of calcium, vitamin D and sun } \\
\text { exposure. }\end{array}$ & $\begin{array}{l}\text { Usual care: standard service } \\
\text { offered for hip fracture in the } \\
\text { area health service, including } \\
\text { orthogeriatric care, rehabilitation } \\
\text { service, other medical and allied } \\
\text { health consultation as required } \\
\text { and physiotherapy. }\end{array}$ \\
\hline
\end{tabular}

Nutrition intervention

Self-guided education resource: provided with French National Nutrition Health Program education booklet-Programme National Nutrition Santé (PNNS).

Nutrition counselling: 7 educational sessions, each $45 \mathrm{~min}$, delivered by a trained researcher or nutritional therapist, twice a week over 3.5-4 weeks. Therapy focused on behavioural change, nutrition optimisation and diabetes.

Supplements: daily ONS with $24 \mathrm{~g}$ whey Usual care: usual medical care, no protein per day $(9 \mathrm{~g}$ breakfast, $7.5 \mathrm{~g}$ at lunch whey protein supplementation. and dinner) in addition to usual diet. Individual supervised exercise: individualised exercises as per intervention.

Nutrition counselling: trained, supervised lay volunteers visit twice/week for dietary discussions aimed at achieving adequate energy, protein and other nutrients. Taught how to enrich food with protein, recipes,

Usual care: usual healthcare from local health system and/or general practitioner. cards and a play board.

Usual care with attention control: trained lay 'buddies' visit twice a week but doing a portfolio of possible activities (go out, have chat and sharing interest), study sites. provided with French National Nutrition Health Program education booklet-PNNS 
Table 3 Continued

\begin{tabular}{|c|c|c|c|}
\hline Study & Exercise intervention & Nutrition intervention & Control intervention \\
\hline Villareal et $a l^{27} \ddagger$ & $\begin{array}{l}\text { Type: strength-65\% of } 1 \mathrm{RM} ; 8-12 \\
\text { repetitions of each exercise (UL, LL) with } \\
\text { options for progression. } \\
\text { Aerobic, } 65 \% \text { of peak HR with gradual } \\
\text { progression to } 70 \%-85 \% \text {. } \\
\text { Flexibility, balance } \\
\text { frequency: } 90 \text { min, } 3 \text { sessions/week. } \\
\text { Setting: inpatient (supervised, group-based). }\end{array}$ & $\begin{array}{l}\text { Nutrition counselling: prescribed a } \\
\text { balanced diet with energy deficit of } \\
500-750 \mathrm{kcal} / \text { day from daily energy } \\
\text { requirement, } 1 \mathrm{~g} \text { of high-quality protein/kg } \\
\text { BW/day. Weekly group consultation with } \\
\text { dietitian for adjustments of their caloric } \\
\text { intake, goals and behavioural therapy. } \\
\text { Supplements: } 1500 \text { mg calcium/day and } \\
\sim 1000 \text { IU vitamin D/day. }\end{array}$ & $\begin{array}{l}\text { Usual care: general healthy } \\
\text { lifestyle advice. } \\
\text { Supplements: } 1500 \mathrm{mg} \text { calcium/ } \\
\text { day and } 1000 \mathrm{IU} \text { vitamin D/day. }\end{array}$ \\
\hline
\end{tabular}

\begin{tabular}{|c|c|c|c|}
\hline Azad et $a l^{46}$ & $\begin{array}{l}\text { Type: 'comprehensive exercise programme'; } \\
\text { type, intensity and target muscle groups NR. } \\
\text { Frequency: } 11 \text { sessions over } \\
6 \text { weeks+NR home exercises. } \\
\text { Setting: inpatient (supervised, group-based), } \\
\text { postdischarge (unsupervised, individual). }\end{array}$ & $\begin{array}{l}\text { Nutrition counselling: } 3 \text { sessions of } \\
\text { individualised counselling about diet and } \\
\text { nutrition in the management of CHF by } \\
\text { dietitian. }\end{array}$ & Usual care: optimal medical care. \\
\hline Blanc-Bisson et $a l^{43}$ & $\begin{array}{l}\text { Type: strength-intensity (RM) NR, 10x } \\
\text { repetitions each exercise (LB). } \\
\text { Frequency: } 30 \text { min, twice/day, } 5 \text { days/week. } \\
\text { Setting: inpatient (supervised, individual). }\end{array}$ & $\begin{array}{l}\text { Meal programme: geriatric hospital meals } \\
\text { of } 1800-2000 \mathrm{kcal} / \text { day. } \\
\text { Supplements: } 1 \text { daily ONS of } 200 \mathrm{kcal} \text { and } \\
15 \mathrm{~g} \text { protein. }\end{array}$ & $\begin{array}{l}\text { Usual care: from day } 3 \text { to } 6 \text {, } \\
\text { patients started to walk with } \\
\text { human help with or without } \\
\text { technical assistance in the } \\
\text { physiotherapy room for three } \\
\text { sessions per week until discharge. } \\
\text { Individual supervised exercise: } \\
\text { physiotherapy continued at home } \\
\text { for } 1 \text { month. }\end{array}$ \\
\hline Miller et $a l^{44}$ & $\begin{array}{l}\text { Type: strength-intensity (RM) NR, } 2 \text { sets of } \\
8 \text { repetitions (LL) with progressive loading, at } \\
\text { the discretion of the treating physiotherapist. } \\
\text { Frequency: } x / \text { week, } 20-30 \text { min/session for } 12 \\
\text { weeks. } \\
\text { Setting: inpatient (supervised, } \\
\text { individual)+postdischarge (supervised, } \\
\text { individual). }\end{array}$ & $\begin{array}{l}\text { Nutrition counselling: individualised } \\
\text { nutrition therapy by dietitian. } \\
\text { Supplements: single type of ONS to cover } \\
\text { the shortfall between individual estimated } \\
\text { energy and protein requirements and actual } \\
\text { intake over } 42 \text { days. }\end{array}$ & $\begin{array}{l}\text { Usual care with attention control } \\
\text { group-received tri-weekly visits } \\
\text { weeks } 1-6 \text {, then weekly visits } \\
7-12 \text { to account for the possibility } \\
\text { of the attention effect. }\end{array}$ \\
\hline
\end{tabular}

Multiple articles reported from same study, study chosen to represent other reports from the same study are mentioned in footnotes * $†$ and $\ddagger$.

*Luger et $a l^{33}$-Haider et $a l,{ }^{34}$ Winzer et $a l^{35}$, Kapan et $a l^{36}$, Kapan et al ${ }^{37}$, Haider et $a l^{38}$.

†Cameron et $\left.a\right|^{29}$-Fairhall et $a l^{30}$, Fairhall et $\left.a\right|^{31}$, Fairhall et al. ${ }^{32}$

$\neq$ Villareal et $a l^{27}$-Armamento-Villareal et $\left.a\right|^{28}$.

BW, body weight; CHF, chronic heart failure; DVD, digital versatile disc; HR, heart rate; LL, lower limb; NR, not reported; ONS, oral nutrition supplements; Otago exercise programme, series of 17 strength and balance at-home exercises for fall prevention programme in frail older adults; RM, repetition max; UL, upper limb; WEBB, Weight-Bearing for Better Balance exercise programme is designed to improve mobility, increase physical activity and prevent falls.

\section{Muscle strength}

The meta-analysis showed no statistically significant differences in muscle strength between participants who received exercise-nutrition intervention and those that received standard care, when handgrip strength was analysed from three studies ${ }^{29} 4048$ (MD 0.46; $95 \%$ CI -0.38 to $\left.0.85 ; \mathrm{p}=0.28 ; \mathrm{I}^{2}=49 \%, \mathrm{p}=0.14\right)$, or, when of handgrip and quadriceps strength was combined ( $n=4$ studies) 29404548 using a published methodology ${ }^{49}$ (SMD 0.10; 95\% CI -0.09 to $0.29 ; \mathrm{p}=0.24, \mathrm{I}^{2}=28 \%, \mathrm{p}=0.30$ ) (figure 3 ).

\section{Nutrition, cognition and biomarkers outcomes}

Most studies assessed participants' nutritional status at baseline, while only one study ${ }^{33}$ assessed it as an outcome. Luger et al reported a 1.54-point improvement in the MNA long form in participants who received exercisenutrition intervention compared with those who received standard care $(95 \%$ CI 0.51 to $2.56, p=0.004)$. Combined exercise-nutrition intervention did not affect cognitive status (Mini-Mental State Examination) or mood (Geriatric Depression Scale). ${ }^{46}$ Armamento-Villareal et al

\section{Frailty}

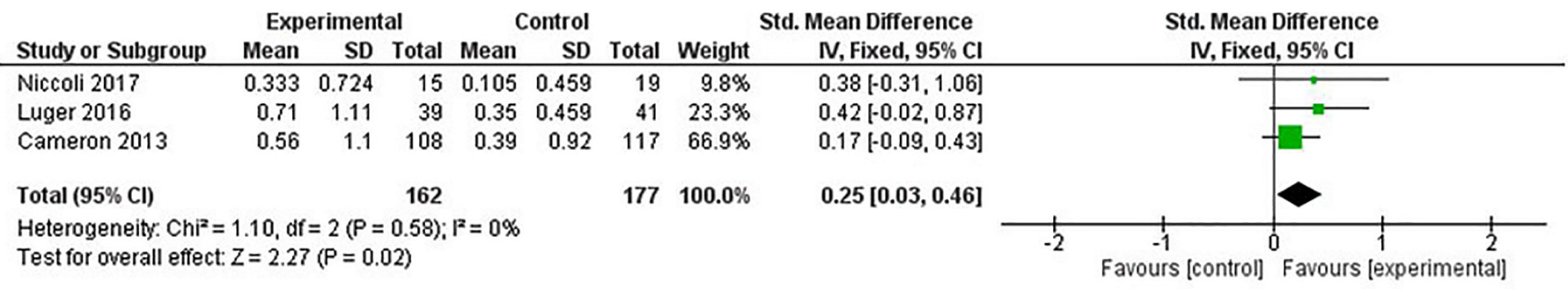

Figure 2 Meta-analysis of reduction in frailty score for exercise and nutrition intervention versus standard care. IV, inverse variance. 
Short Physical Performance Battery

\begin{tabular}{lrrrrrrrr} 
& \multicolumn{3}{c}{ Experimental } & \multicolumn{2}{c}{ Control } & \multicolumn{2}{c}{ Mean Difference } \\
Study or Subgroup & Mean & SD & Total & Mean & SD & Total & Weight & I, Fixed, 95\% CI \\
\hline Rodriguez-Manas 2019 & 0.82 & 3.66 & 233 & -0.12 & 3.66 & 381 & $35.9 \%$ & $0.94[0.34,1.54]$ \\
Haider 2017 & 1.2 & 2.78 & 39 & 0.5 & 3.17 & 41 & $7.5 \%$ & $0.70[-0.60,2.00]$ \\
Cameron 2013 & 0.15 & 1.89 & 107 & -0.01 & 1.72 & 116 & $56.5 \%$ & $0.16[-0.32,0.64]$ \\
Total (95\% Cl) & & & & & & & &
\end{tabular}

Heterogeneity: $\mathrm{Chi}^{2}=4.13, \mathrm{df}=2(P=0.13) ; \mathrm{I}^{2}=52 \%$

Test for overall effect: $Z=2.64(P=0.008)$

Mean Difference

IV, Fixed, $95 \% \mathrm{Cl}$

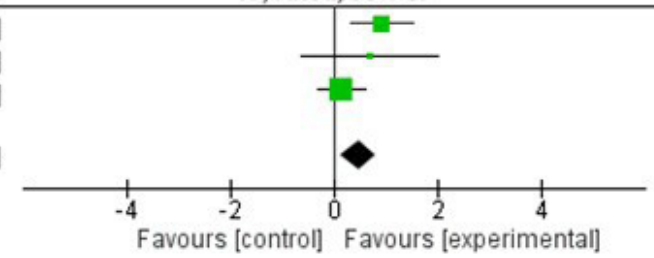

Gait Speed

\begin{tabular}{|c|c|c|c|c|c|c|c|c|}
\hline \multirow[b]{2}{*}{ Study or Subgroup } & \multicolumn{3}{|c|}{ Experimental } & \multicolumn{3}{|c|}{ Control } & \multicolumn{2}{|r|}{ Mean Difference } \\
\hline & Mean & SD & Total & Mean & SD & Total & Weight & N, Fixed, $95 \% \mathrm{Cl}$ \\
\hline Rodriguez-Manas 2019 & 0.14 & 1.56 & 233 & -0.11 & 1.56 & 381 & $2.5 \%$ & $0.25[-0.00,0.50]$ \\
\hline Niccoli 2017 & 0.16 & 0.169 & 22 & 0.18 & 0.792 & 25 & $1.6 \%$ & $-0.02[-0.34,0.30]$ \\
\hline Haider 2017 & 0.2 & 1.233 & 39 & -0.1 & 0.792 & 41 & $0.8 \%$ & $0.30[-0.16,0.76]$ \\
\hline Cameron 2013 & 0.006 & 0.155 & 120 & -0.007 & 0.169 & 121 & $95.2 \%$ & $0.01[-0.03,0.05]$ \\
\hline
\end{tabular}

Heterogeneity: $\mathrm{Chi}^{2}=4.76, \mathrm{df}=3(\mathrm{P}=0.19) ; \mathrm{I}^{2}=37 \%$

$100.0 \% \quad 0.02[-0.02,0.06]$

Test for overall effect. $Z=1.01(P=0.31)$

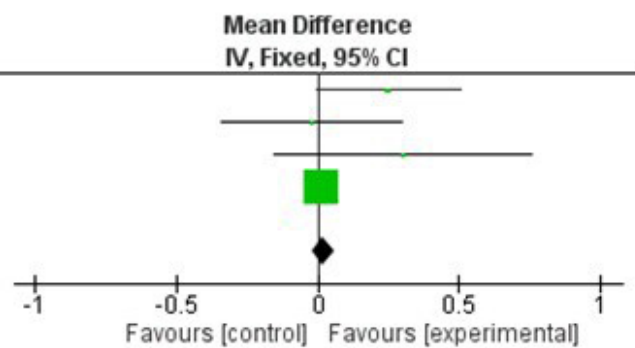

Balance

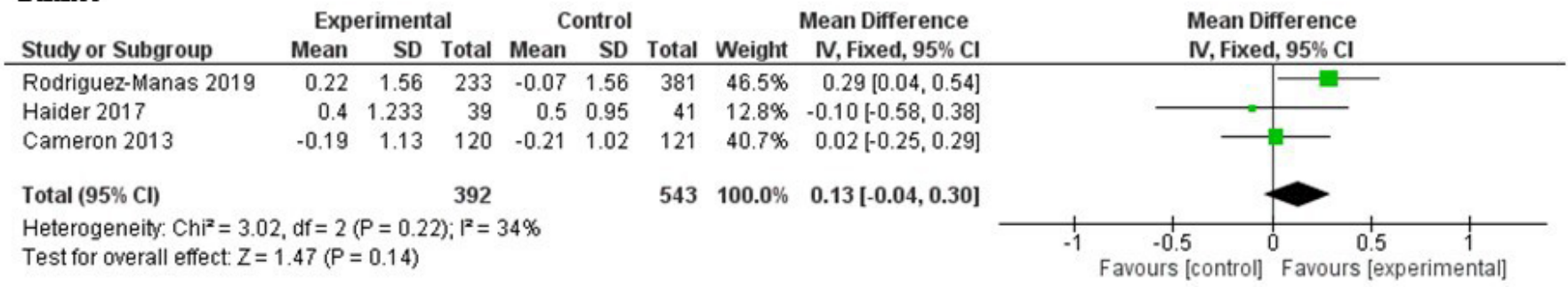

Chair Stand Test

\begin{tabular}{llllll} 
& \multicolumn{2}{c}{ Experimental } & \multicolumn{2}{c}{ Control } & \multicolumn{2}{c}{ Mean Difference } \\
Study or Subgroup & Mean & SD Total Mean & SD Total Weight IV, Fixed, $95 \% \mathrm{Cl}$
\end{tabular}

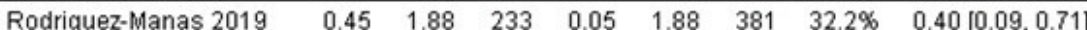

Haider 2017

$\begin{array}{llllllll}0.6 & 1.233 & 39 & 0.1 & 1.267 & 41 & 10.1 \% & 0.50[-0.05,1.05\end{array}$

Cameron 2013

$\begin{array}{lllll}0.26 & 0.94 & 120 & 0.12 & 0.87\end{array}$

$121 \quad 57.8 \% \quad 0.14[-0.09,0.37]$

Total $(95 \% \mathrm{Cl})$

392

$543 \quad 100.0 \% \quad 0.26[0.09,0.43]$

Heterogeneity $\mathrm{Chi}^{2}=2.60, \mathrm{df}=2(\mathrm{P}=0.27) ; \mathrm{I}^{2}=23 \%$

Test for overall effect: $Z=2.93(P=0.003)$

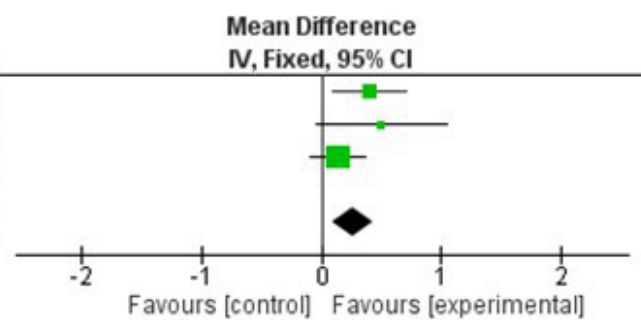

Activities of Daily Living

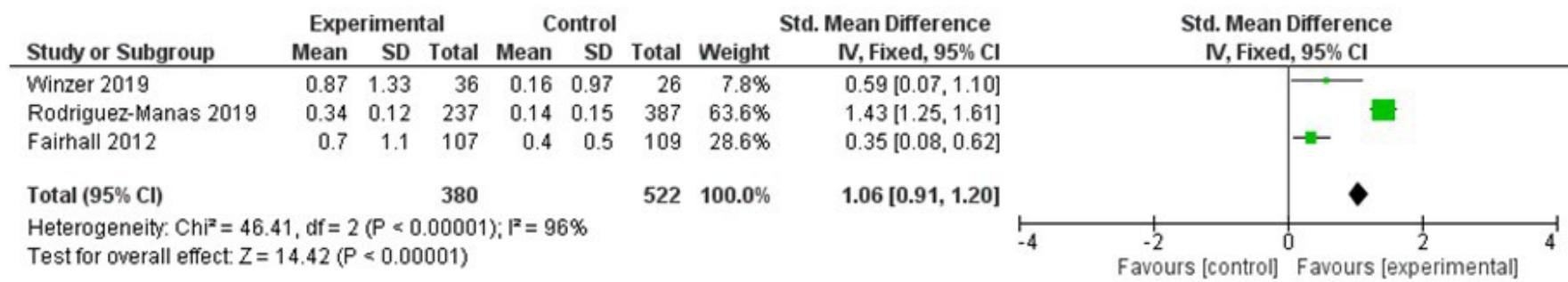

Handgrip Strength

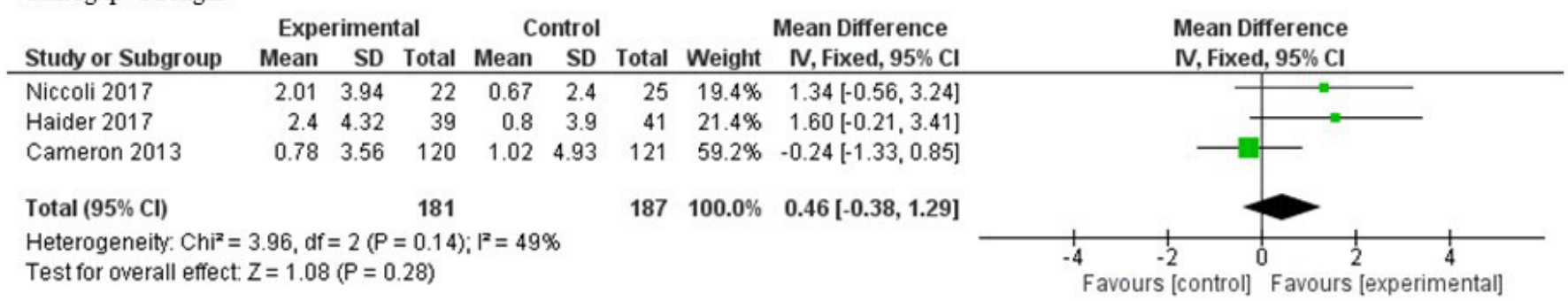

Abbreviations: CI confidence interval; $I V$ inverse variance; $S D$ standard deviation

Figure 3 Meta-analyses of short physical performance battery, gait speed, balance test, chair stand test, activities of daily living, handgrip strength. IV, inverse variance. 
reported a significant decrease in total and free estradiol in their frail older men with obesity (attributed to weight loss from lifestyle change rather than the intervention), without a clinically meaningful increase in total or free testosterone levels. ${ }^{28} \mathrm{In}$ one study that reported $\mathrm{C}$ reactive protein levels, this inflammatory marker remained stable in the exercise-nutrition intervention group participants, compared with an increase in the social support control group at the end of 12 weeks $(p=0.04){ }^{38}$

\section{Quality of life and falls}

Three studies $^{32}{ }^{37} 41$ that evaluated QoL did not find a statistically significant improvement in the intervention as compared with the control group, although Milte $e t$ $a t^{41}$ found a trend favouring intervention. Fairhall $e t a l^{31}$ found that risk factors related to falls (physical tests as mentioned above) but not rate of falls were reduced while Kapan $e t a \hat{l}^{36}$ found that a $10 \%$ reduction in fear of falling as ascertained by the falls efficacy scale.

\section{Economic analyses}

Only two studies examined the cost-effectiveness of their exercise-nutrition intervention. Fairhall $e t a l^{32}$ reported no additional resource cost in terms of medical $(\mathrm{p}=0.87)$ or nursing and health professional appointments $(\mathrm{p}=0.32)$. Similarly, Milte $e t a t^{41}$ reported no cost differences between groups $(\mathrm{p}=0.868)$.

\section{DISCUSSION}

\section{Main findings}

The present systematic review and meta-analysis present updated evidence that suggests exercise with nutrition intervention to be effective on frailty and frailty-related physical outcomes in hospitalised older adult patients. When compared with standard care, combined exercisenutrition interventions improved frailty status as determined by the Fried Frailty criteria ${ }^{2}$ and the SHARE-FI. ${ }^{47}$ They also improved physical function according to the SPPB and ADLs. Only one study measured and found significant improvement in nutrition score. ${ }^{33}$ The two economic analyses included in this review suggested that combined exercise-nutrition interventions, although more effective, were no more costly than standard care.

Existing reviews of exercise and nutrition interventions have highlighted heterogeneity in study protocols (including intervention descriptions), which limits potential for quantitative analysis. They have also focused on community dwelling participants. ${ }^{50}$ This study is novel in reviewing a more vulnerable hospitalised population that has not been previously investigated, and specifically targeting prefrail or frail older adults. However, out of five studies in this review that used a validated frailty assessment tool, only three had assessed frailty at outcome, and available for quantitative analysis. This could be because the frailty phenotype was first described 2001, with a systematic evaluation of frailty tools a decade later. ${ }^{2} 51$ Accordingly, the authors decided to additionally evaluate frailty components such as physical function, nutrition, cognition and biomarkers as baseline and outcome measures. Although not specific to frailty, these measures provide insights to the effectiveness of exercise-nutrition interventions on improving various components of frailty and may inform future studies.

Previous reviews have found mixed results ${ }^{50}$ or have concluded that evidence for combined interventions is limited but increasing. ${ }^{52}$ Our results concur with RCTs of exercise-nutrition interventions conducted in community dwelling frail older adults. Tarazona-Santabalbina $e t$ al found significant improvement in SPPB in participants on a 24-week exercise-nutrition intervention as compared with controls in a community dwelling frail populationintervention group $9.5 \pm 1.8 \mathrm{vs}$ control group $7.1 \pm 2.8$, $\mathrm{p}=0.0070 .{ }^{53}$ Similarly, Kim et al reported a 12-week, community-based study of frail older adults that found SPPB to remain stable in the intervention group, while it decreased by $12.5 \%$ ( 1 point) in controls $(\mathrm{p}=0.039) .{ }^{54}$ Our meta-analysis of individual components of the SPPB suggests that the significant improvements in functional muscle strength as represented by the chair stand component of the SPPB may be pivotal to the increase in overall SPPB postintervention, and reflect the functional lower limb strength training focus of the exercise interventions. However, the meta-analysis of handgrip \pm quadriceps strength did not produce a similar trend. Diversity in outcome measures for frailty and frailty-related domains like physical function is a challenge for comparative analyses between studies. Future studies should carefully consider measure responsiveness when selecting outcome tools.

Nutrition is another important domain within frailty. Yet the majority of studies included in this review only reported nutrition status at baseline, with only one study reporting follow-up nutrition assessment at the end of the intervention. ${ }^{33}$ Luger $e t$ al described an improvement in nutrition status in a sample of at-risk malnourished prefrail/frail patients (thus likely to benefit most from nutrition therapy). As hospitalised patients have greater energy deficits due to catabolic stress of acute illness, they are a population that requires careful determination of energy/protein requirements and in whom additive effects of nutrition supplementation to exercise may have greatest impact on outcomes such as muscle strength. ${ }^{53}$ As none of the studies in the present review reported on energy deficits, it is not known whether these patients received adequate replacement. Nutrition supplementation should also not be confused with nutrition or diet modifications. The provision of ONS alone is unlikely to augment diet adequacy as completely as diet modification that involves a wider range of nutrients and nonnutrients ${ }^{55}$ especially when led by dietitians. ${ }^{5657}$

For both exercise and nutrition-based interventions, an understanding of patient participation dynamics and compliance is required because of how they can impact on effectiveness. ${ }^{58}$ Only five studies in this review reported attendance to programme/home visits or phone calls or 
adherence to prescribed exercise/diet or related advice at rates of $50 \%-90 \%$ and $70 \%-93 \%$ for nutrition and exercise interventions, respectively. Issues with participants resulting in poorer compliance were not reported in these articles, such that the authors recommend that future studies explore barriers and enablers to adherence in multimodal interventions.

Cognition is another critical domain in the multidimensional nature of frailty. Exercise ${ }^{59}$ and nutrition interventions ${ }^{60}$ may have a far-reaching, positive effect on cognition in older adults. However, there was no evidence of an impact on cognition from a single study ${ }^{42}$ in the present review. This is consistent with a network metaanalysis of 13 RCTs that examined exercise and nutrition interventions in frail older adults. ${ }^{11}$ One suggested explanation is that different neuronal mechanisms could result in a misfit between combinatory approaches of nutrition and physical interventions ${ }^{61}$ highlighting that more in-depth research is required. ${ }^{62}$

The economic delivery of new interventions and models of care is important to a range of stakeholders, ${ }^{63}$ but has been infrequently conducted in previous studies. ${ }^{50}$ In this review, only 2 out of 11 studies included an economic analysis, with the majority of costs coming from delivery of exercise and nutrition support. The types of consumables that were considered in analyses included nutrition supplements, ankle/wrist weights, mobility aids and medications. Elements of service provision that were considered included community, rehabilitation, residential and transition care service use, which were often reduced and contributed to the net result. The results of this review support previous findings of beneficial effects on frailtyrelated outcomes, without increased costs. ${ }^{50}$ However, results should be interpreted with caution as omission of other services (such as medication reviews) within a multimodal intervention can impact costings, and there are instances where interventions have not been found to be more-cost effective than usual care. ${ }^{64}$ The approach of streamlining and reorganising existing services rather than creating entirely new systems may be preferred.

\section{Strength and weakness}

This study was robust and underwent peer review by an academic librarian. We did not have a language restriction on the search, and we did not find nor include studies in other languages. We chose to use an updated version of the Cochrane risk-of-bias tool (RoB-2), which addresses issues of confusion common to its first version.

By focussing on exercise-nutrition interventions only, this study addresses a gap as identified in a recent review of multidomain interventions in prefrail or frail elderly adults, in which some interventions may have been be too broad to directly impact frailty, and functional and cognitive status. ${ }^{52}$ Multidisciplinary team-based approaches remain recommended and are a bedrock of quality standard care; they may also already include goals for exercise and nutrition such that it may be difficult to solely attribute outcomes to a targeted but supplementary exercise-nutrition programme. Social relationships affect health behaviour and physical health, ${ }^{65}$ such that intervention benefits may in part come from social interactions. Nevertheless, several studies ${ }^{29} 3344$ have demonstrated significant improvements even when control participants are provided with the social aspect of an intervention, such that exercise and nutrition are expected to improve outcomes independent of social interactions. Among the three studies ${ }^{2933}$ included in the meta-analysis of reduction in frailty score, one study ${ }^{33}$ included patients from community. However, when combined with data from the other two studies, ${ }^{29} 40$ participants recruited from the hospital made up majority $(\sim 80 \%)$ of the entire cohort in that meta-analysis.

\section{Implications and future research}

This review is a useful resource for researchers and multidisciplinary clinicians who are seeking to generate evidence or evaluate their practices of exercise-nutrition interventions for pre-frail/frail hospitalised older adults. The authors interpretation of the quality of studies in this review is that the evidence base is low, but the inclusion of future studies may change estimates of the intervention effects. While blinding of participants to the intervention is acknowledged to be difficult, future studies should be adequately powered, use allocation concealment with blinding outcome assessors and data analysts at least. Improved reporting of intervention details is also required, ${ }^{66}$ which may assist in answering research questions around the optimal duration, dose, modality and timing of intervention(s) across the hospital to community continuum. In the present review, potential beneficial effects of combined interventions could have been negated given the short durations reported by most studies. Thus, future studies may be extended for $>6-12$ months, or employ principles of chronic condition self-management, ${ }^{67}$ to determine delayed improvements and achieve long-lasting sustainability of interventions. The lack of evidence from non-western countries, or lowincome and middle-income countries indicate the need for research to be conducted in those populations too. There are many ongoing research activities relevant to the scope of this review, ${ }^{6-71}$ yet only one has reported plans for economic analysis in the study protocol.$^{68}$ Economic evaluations can expand current evidence on the sustainability of incorporating such services within resourceconstrained healthcare systems.

\section{CONCLUSION}

Exercise-nutrition interventions that start while patients are admitted to hospital and continue in the community/ posthospital, or, commence early postdischarge, appear to be effective in reducing frailty and some frailty-related physical indicators. Although effective, the quality of the evidence in this review is low as most studies included had some concerns for risk of bias. Given the paucity of high-quality studies on the effectiveness of combined 
exercise-nutrition interventions on hospitalised frail older adult patients, more robust research that pays attention to effect of assignment to intervention is needed to increase the confidence in results.

Acknowledgements The authors would like to thank the librarians at Gus Fraenkel Medical Library, Flinders University for their support with the study.

Contributors All authors contributed to the conception and design of review. CYH and YS read and screened titles and abstract of potentially relevant studies. $\mathrm{CH}$ and YS evaluated the selected studies and performed data extraction. CYH, MM, AY, $C B$ reviewed the evidence. RW provided statistical expertise on meta-analyses. $\mathrm{CYH}$ drafted the article and all authors provided critical revisions and final approval of the manuscript. All authors had access to the data in the study and can take responsibility for the integrity of the reported findings. All authors fulfil the ICMJE criteria for authorship.

Funding The authors have not declared a specific grant for this research from any funding agency in the public, commercial or not-for-profit sectors.

Competing interests None declared.

Patient consent for publication Not required.

Provenance and peer review Not commissioned; externally peer reviewed.

Data availability statement Data may be obtained from a third party and are not publicly available. No data are available. Details of the excluded papers are available from the corresponding author on request.

Supplemental material This content has been supplied by the author(s). It has not been vetted by BMJ Publishing Group Limited (BMJ) and may not have been peer-reviewed. Any opinions or recommendations discussed are solely those of the author(s) and are not endorsed by BMJ. BMJ disclaims all liability and responsibility arising from any reliance placed on the content. Where the content includes any translated material, BMJ does not warrant the accuracy and reliability of the translations (including but not limited to local regulations, clinical guidelines, terminology, drug names and drug dosages), and is not responsible for any error and/or omissions arising from translation and adaptation or otherwise.

Open access This is an open access article distributed in accordance with the Creative Commons Attribution Non Commercial (CC BY-NC 4.0) license, which permits others to distribute, remix, adapt, build upon this work non-commercially, and license their derivative works on different terms, provided the original work is properly cited, appropriate credit is given, any changes made indicated, and the use is non-commercial. See: http://creativecommons.org/licenses/by-nc/4.0/.

\section{ORCID iDs}

Chad Yixian Han http://orcid.org/0000-0002-0756-6344

Yogesh Sharma http://orcid.org/0000-0002-7716-2599

\section{REFERENCES}

1 Le Cossec C, Perrine A-L, Beltzer N, et al. Pre-frailty, frailty, and multimorbidity: prevalences and associated characteristics from two French national surveys. J Nutr Health Aging 2016;20:860-9.

2 Fried LP, Tangen CM, Walston J, et al. Frailty in older adults: evidence for a phenotype. The Journals of Gerontology Series A: Biological Sciences and Medical Sciences 2001;56:M146-57.

3 Theou O, Squires E, Mallery K, et al. What do we know about frailty in the acute care setting? A scoping review. BMC Geriatr 2018;18:139.

4 Considine J, Fox K, Plunkett D, et al. Factors associated with unplanned readmissions in a major Australian health service. Aust. Health Review 2019;43:1-9.

5 Sirven N, Rapp T. The cost of frailty in France. Eur $J$ Health Econ 2017;18:243-53.

6 Thompson MQ, Theou O, Karnon J, et al. Frailty prevalence in Australia: findings from four pooled Australian cohort studies. Australas J Ageing 2018;37:155-8.

7 Giné-Garriga M, Roqué-Fíguls M, Coll-Planas L, et al. Physical exercise interventions for improving performance-based measures of physical function in community-dwelling, frail older adults: a systematic review and meta-analysis. Arch Phys Med Rehabil 2014;95:753-69.

8 TP N, Feng L, Nyunt MS, et al. Nutritional, physical, cognitive, and combination interventions and frailty reversal among older adults: a randomized controlled trial. Am J Med 2015;128:1225-36.
9 Hsieh T-J, Su S-C, Chen C-W, et al. Individualized home-based exercise and nutrition interventions improve frailty in older adults: a randomized controlled trial. Int J Behav Nutr Phys Act 2019;16:119.

10 Lozano-Montoya I, Correa-Pérez A, Abraha I, et al. Nonpharmacological interventions to treat physical frailty and sarcopenia in older patients: a systematic overview - the Senator Project ontop Series. Clin Interv Aging 2017;12:721-40.

11 Abizanda P, López MD, García VP, et al. Effects of an oral nutritional supplementation plus physical exercise intervention on the physical function, nutritional status, and quality of life in frail institutionalized older adults: the activnes study. J Am Med Dir Assoc 2015;16:439. e9-439.e16.

12 Negm AM, Kennedy CC, Thabane L, et al. Management of frailty: a systematic review and network meta-analysis of randomized controlled trials. J Am Med Dir Assoc 2019;20:1190-8.

13 Rozzini R, Sabatini T, Cassinadri A, et al. Relationship between functional loss before hospital admission and mortality in elderly persons with medical illness. J Gerontol A Biol Sci 2005;60:1180-3.

14 Covinsky KE, Martin GE, Beyth RJ, et al. The relationship between clinical assessments of nutritional status and adverse outcomes in older hospitalized medical patients. J Am Geriatr Soc 1999;47:532-8.

15 Sharma Y, Thompson C, Shahi R, et al. Malnutrition in acutely unwell hospitalized elderly - "The skeletons are still rattling in the hospital closet". J Nutr Health Aging 2017;21:1210-5.

16 Sharma Y, Miller M, Shahi R, et al. Malnutrition screening in acutely unwell elderly inpatients. British Journal of Nursing 2016;25:1006-14

17 Laur CV, McNicholl T, Valaitis R, et al. Malnutrition or frailty? overlap and evidence gaps in the diagnosis and treatment of frailty and malnutrition. Appl Physiol Nutr Metab 2017;42:449-58.

18 Rasmussen NML, Belqaid K, Lugnet K, et al. Effectiveness of multidisciplinary nutritional support in older hospitalised patients: a systematic review and meta-analyses. Clinical Nutrition ESPEN 2018;27:44-52

19 Wilkinson R, Arensberg ME, Hickson M, et al. Frailty prevention and treatment: why registered dietitian Nutritionists need to take charge. $J$ Acad Nutr Diet 2017;117:1001-9.

20 Higgins JP, Green S. Cochrane Handbook for systematic reviews of interventions: cochrane book series, 2008.

21 Moher D, Liberati A, Tetzlaff J, et al. Preferred reporting items for systematic reviews and meta-analyses: the PRISMA statement. $J$ Clin Epidemiol 2009;62:1006-12.

22 Innovation VH. Covidence systematic review software. Veritas Health Innovation Melbourne, VIC, 2017.

23 Sterne JAC, Savović J, Page MJ, et al. Rob 2: a revised tool for assessing risk of bias in randomised trials. BMJ 2019;2:14898. doi:10.1136/bmj.14898

24 Farrah K, Young K, Tunis MC, et al. Risk of bias tools in systematic reviews of health interventions: an analysis of PROSPERO-registered protocols. Syst Rev 2019;8:280.

25 RevMan. Review manager (revman)[computer program. version 5.3. Denmark: The Nordic Cochrane Centre, The Cochrane Collaboration Copenhagen, 2014.

26 Higgins JPT, Thompson SG, Deeks JJ. Measuring inconsistency in meta-analyses. BMJ 2003;327:557-60.

27 Villareal DT, Chode S, Parimi N, et al. Weight loss, exercise, or both and physical function in obese older adults. N Engl J Med 2011;364:1218-29.

28 Armamento-Villareal R, Aguirre LE, Qualls C, et al. Effect of lifestyle intervention on the hormonal profile of frail, obese older men. J Nutr Health Aging 2016;20:334-40.

29 Cameron ID, Fairhall N, Langron C, et al. A multifactorial interdisciplinary intervention reduces frailty in older people: randomized trial. BMC Med 2013;11:65.

30 Fairhall N, Sherrington C, Kurrle SE, et al. Effect of a multifactoria interdisciplinary intervention on mobility-related disability in frail older people: randomised controlled trial. BMC Med 2012;10:120.

31 Fairhall N, Sherrington C, Lord SR, et al. Effect of a multifactorial, interdisciplinary intervention on risk factors for falls and fall rate in frail older people: a randomised controlled trial. Age Ageing 2014;43:616-22.

32 Fairhall N, Sherrington C, Kurrle SE, et al. Economic evaluation of a multifactorial, interdisciplinary intervention versus usual care to reduce frailty in frail older people. J Am Med Dir Assoc 2015;16:41-8.

33 Luger E, Dorner TE, Haider S, et al. Effects of a home-based and Volunteer-Administered physical training, nutritional, and socia support program on malnutrition and frailty in older persons: a randomized controlled trial. J Am Med Dir Assoc 2016;17:671. e9-671.e16.

34 Haider S, Dorner TE, Luger E, et al. Impact of a home-based physical and nutritional intervention program conducted by Lay-Volunteers 
on handgrip strength in Prefrail and frail older adults: a randomized control trial. PLoS One 2017;12:e0169613.

35 Winzer E, Dorner TE, Grabovac I, et al. Behavior changes by a buddy-style intervention including physical training, and nutritional and social support. Geriatr Gerontol Int 2019;19:323-9.

36 Kapan A, Luger E, Haider S, et al. Fear of falling reduced by a lay led home-based program in frail community-dwelling older adults: a randomised controlled trial. Arch Gerontol Geriatr 2017;68:25-32.

37 Kapan A, Winzer E, Haider S, et al. Impact of a lay-led home-based intervention programme on quality of life in community-dwelling prefrail and frail older adults: a randomized controlled trial. BMC Geriatr 2017;17:1-11.

38 Haider S, Grabovac I, Winzer E, et al. Change in inflammatory parameters in prefrail and frail persons obtaining physical training and nutritional support provided by lay volunteers: a randomized controlled trial. PLoS One 2017;12:e0185879.

39 Arrieta $\mathrm{H}$, Astrugue $\mathrm{C}$, Regueme S, et al. Effects of a physical activity programme to prevent physical performance decline in onco-geriatric patients: a randomized multicentre trial. J Cachexia Sarcopenia Muscle 2019;10:287-97.

40 Niccoli S, Kolobov A, Bon T, et al. Whey protein supplementation improves rehabilitation outcomes in hospitalized geriatric patients: a double blinded, randomized controlled trial. J Nutr Gerontol Geriatr 2017;36:149-65.

41 Milte R, Miller M, Crotty M, et al. Cost-Effectiveness of individualized nutrition and exercise therapy for rehabilitation following hip fracture. $J$ Rehabil Med 2016;48:378-85.

42 Singh NA, Quine S, Clemson LM, et al. Effects of high-intensity progressive resistance training and targeted multidisciplinary treatment of frailty on mortality and nursing home admissions after hip fracture: a randomized controlled trial. J Am Med Dir Assoc 2012;13:24-30.

43 Blanc-Bisson C, Dechamps A, Gouspillou G, et al. A randomized controlled trial on early physiotherapy intervention versus usual care in acute CAR unit for elderly: potential benefits in light of dietary intakes. J Nutr Health Aging 2008;12:395-9.

44 Miller MD, Crotty M, Whitehead C, et al. Nutritional supplementation and resistance training in nutritionally at risk older adults following lower limb fracture: a randomized controlled trial. Clin Rehabil 2006;20:311-23.

45 Rodriguez-Mañas L, Laosa O, Vellas B, et al. Effectiveness of a multimodal intervention in functionally impaired older people with type 2 diabetes mellitus. J Cachexia Sarcopenia Muscle 2019;10:721-33.

46 Azad N, Molnar F, Byszewski A. Lessons learned from a multidisciplinary heart failure clinic for older women: a randomised controlled trial. Age Ageing 2008;37:282-7.

47 Romero-Ortuno R, Walsh CD, Lawlor BA, et al. A frailty instrument for primary care: findings from the survey of health, ageing and retirement in Europe (share). BMC Geriatr 2010;10:57.

48 Haider S, Dorner TE, Luger E, et al. Impact of a home-based physical and nutritional intervention program conducted by lay-volunteers on handgrip strength in prefrail and frail older adults: a randomized control trial. PLoS One 2017;12:e0169613.

49 Wright J, Baldwin C. Oral nutritional support with or without exercise in the management of malnutrition in nutritionally vulnerable older people: a systematic review and meta-analysis. Clinical Nutrition 2018;37:1879-91.

50 Apóstolo J, Cooke R, Bobrowicz-Campos E, et al. Effectiveness of interventions to prevent pre-frailty and frailty progression in older adults. JBI Database of Systematic Reviews and Implementation Reports 2018;16:140-232.

51 de Vries NM, Staal JB, van Ravensberg CD, et al. Outcome instruments to measure frailty: a systematic review. Ageing Res Rev 2011;10:104-14.

52 Dedeyne L, Deschodt M, Verschueren S, et al. Effects of multidomain interventions in (pre)frail elderly on frailty, functional, and cognitive status: a systematic review. Clin Interv Aging 2017:12:873-96.

53 Tarazona-Santabalbina FJ, Gómez-Cabrera MC, Pérez-Ros P, et al. A multicomponent exercise intervention that reverses frailty and improves cognition, emotion, and social networking in the community-dwelling frail elderly: a randomized clinical trial. J Am Med Dir Assoc 2016;17:426-33.

$54 \mathrm{Kim}$ C-O, Lee K-R. Preventive effect of protein-energy supplementation on the functional decline of frail older adults with low socioeconomic status: a community-based randomized controlled study. J Gerontol A Biol Sci 2013;68:309-16.

55 Denison HJ, Cooper C, Sayer AA, et al. Prevention and optimal management of sarcopenia: a review of combined exercise and nutrition interventions to improve muscle outcomes in older people. Clin Interv Aging 2015;10:859.

56 Munk T, Tolstrup U, Beck AM, et al. Individualised dietary counselling for nutritionally at-risk older patients following discharge from acute hospital to home: a systematic review and meta-analysis. J Hum Nutr Diet 2016;29:196-208.

57 Beck AM, Kjær S, Hansen BS, et al. Follow-Up home visits with registered dietitians have a positive effect on the functional and nutritional status of geriatric medical patients after discharge: a randomized controlled trial. Clin Rehabil 2013;27:483-93.

58 Fairhall N, Sherrington C, Cameron ID, et al. A multifactorial intervention for frail older people is more than twice as effective among those who are compliant: complier average causal effect analysis of a randomised trial. J Physiother 2017;63:40-4.

59 Brisswalter J, Collardeau M, René A. Effects of acute physical exercise characteristics on cognitive performance. Sports Medicine 2002;32:555-66.

60 Klímová B, Vališ M. Nutritional interventions as beneficial strategies to delay cognitive decline in healthy older individuals. Nutrients 2018:10:905

61 Schättin A, Baur K, Stutz J, et al. Effects of physical exercise combined with nutritional supplements on aging brain related structures and functions: a systematic review. Front Aging Neurosci 2016;8:161

62 Hardman RJ, Kennedy G, Macpherson H, et al. A randomised controlled trial investigating the effects of Mediterranean diet and aerobic exercise on cognition in cognitively healthy older people living independently within aged care facilities: the Lifestyle Intervention in Independent Living Aged Care (LIILAC) study protocol [ACTRN12614001133628]. Nutr J 2015;14:53.

63 Drummond MF, Stoddart GL. Economic analysis and clinical trials. Control Clin Trials 1984;5:115-28.

64 Ruikes FGH, Adang EM, Assendelft WJJ, et al. Cost-Effectiveness of a multicomponent primary care program targeting frail elderly people. BMC Fam Pract 2018;19:62.

65 Umberson D, Karas Montez J. Social relationships and health: a flashpoint for health policy. J Health Soc Behav 2010;51:S54-66.

66 Hoffmann TC, Glasziou PP, Boutron I, et al. Better reporting of interventions: template for intervention description and replication (TIDieR) checklist and guide. BMJ 2014;348:g1687.

67 Battersby M, Harris M, Smith D, et al. A pragmatic randomized controlled trial of the Flinders program of chronic condition management in community health care services. Patient Educ Couns 2015;98:1367-75.

68 Fairhall N, Kurrle SE, Sherrington C, et al. Effectiveness of a multifactorial intervention on preventing development of frailty in prefrail older people: study protocol for a randomised controlled trial. BMJ Open 2015;5:e007091.

69 González-Sánchez M, Cuesta-Vargas Al, del Mar Rodríguez González M, et al. Effectiveness of a muticomponent workout program integrated in an evidence based multimodal program in hyperfrail elderly patients: POWERAGING randomized clinical trial protocol. BMC Geriatr 2019;19.

70 Jadczak AD, Luscombe-Marsh N, Taylor P, et al. The express study: exercise and protein effectiveness supplementation study supporting autonomy in community dwelling frail older people-study protocol for a randomized controlled pilot and feasibility study. Pilot Feasibility Stud 2018;4:8

71 Landi F, Cesari M, Calvani R, et al. The "Sarcopenia and Physical fRailty IN older people: multi-componenT Treatment strategies" (SPRINTT) randomized controlled trial: design and methods. Aging Clin Exp Res 2017;29:89-100. doi:10.1007/s40520-016-0715-2 